\title{
Molecular Modeling Analyses for Polypropylene/Zinc Oxide Nanocomposite
}

\author{
Ahmed Abdel Moez ${ }^{1}$, Ahmed Fahmy ${ }^{2}$, Hend Ezzat ${ }^{3}$ (D), Asmaa M. Ibrahim 4 (D), Dina Shehata ${ }^{1}$, Hanan \\ Elhaes 1 (D), Medhat A. Ibrahim 5 , * (D)
}

1 Semiconductor Laboratory, Solid State Physics Department, Physics Research Division, National Research Centre, 33 ElBohouth Street, Dokki, Giza 12622, Egypt

2 Physics Department, Faculty of Women for Arts, Science and Education, Ain Shams University, 11757 Cairo, Egypt

3 Nano Technology Unit, Space Lab, Solar, and Space Research Department, National Research Institute of Astronomy and Geophysics (Nano NRIAG), 11731 Helwan, Cairo, Egypt

4 October High Institute For Engineering \& Technology, 6th October City, Giza, Egypt

5 Molecular Spectroscopy and Modeling Unit, Spectroscopy Department, National Research Centre, 33 El-Bohouth St., 12622, Dokki, Giza, Egypt

* Correspondence: medahmed6@yahoo.com;

Scopus Author ID 8641587100

Received: 31.10.2020; Revised: 2.12.2020; Accepted: 3.12.2020; Published: 10.12.2020

\begin{abstract}
Molecular modeling is an important tool for elucidating the electronic properties of polymers as well as polymers interacting with metal oxides. In this sense, Polypropylene (PP) is a synthetic and thermoplastic polymer with high electrical resistivity. A computational study based on density functional theory was established to study the effect of the addition of metal oxide such as zinc oxide $(\mathrm{ZnO})$ on the electronic properties of PP. DFT theory at B3LYB/6-311g (d, p) level was chosen to study $\mathrm{PP}$ electronic properties and $\mathrm{PP} / \mathrm{ZnO}$ nanocomposite. According to the results of total dipole moment (TDM) and HOMO/LUMO bandgap energy calculations, the studied model structures' reactivity for nanocomposite increased due to the addition of metal oxide. The values of the energy bandgap decreased due to the interaction of metal oxide with the original polymer.
\end{abstract}

Keywords: polypropylene; ZnO; DFT; TDM and HOMO/LUMO band gap.

(C) 2020 by the authors. This article is an open-access article distributed under the terms and conditions of the Creative Commons Attribution (CC BY) license (https://creativecommons.org/licenses/by/4.0/).

\section{Introduction}

Polypropylene (PP) is a semi-crystalline and thermoplastic polymer which commonly used as nanocomposites. PP is widely used for such study according to its flexible structure, mechanical properties, and optical properties. PP nanocomposites are extensively applied for packaging, automotive, electrical/electronic, and aerospace applications [1]. Owing to PP has special features as adaptation flexibility, thermal resistivity highly strength, lightweight, and low effective cost [2]. PP nanocomposites have excessive attention recently, according to properties improvement. Appropriate nanofiller makes expressive improvements in polymer properties mechanically, optically, electrically, and thermally [3-9] to be applied for various applications [10-13]. $\mathrm{PP} / \mathrm{ZnO}$ nanocomposite conveyed significant enhancement in crystallization, tensile strength, resistance, and impact strength [14,15] and growing in dynamical, mechanical properties, and thermal stability [16]. Also, $\mathrm{PP}$ with $\mathrm{CaCO}_{3}$ as filler is 
widely used according to low cost. It improves physical, thermal stability, and mechanical properties [17].

Moreover, nanocomposite PP could be applied in environmental applications [18]. PP/ $\mathrm{TiO}_{2}$ nanofibers were prepared for biomaterial applications as antibacterial [19]. PP/ organophilic clay nanocomposites injected also recorded improved mechanical properties compared with PP according to flexural, impact, and strength results [20]. Meanwhile, PP/Multiwall carbon nanotubes (MWCNT) important upgrading in PP properties [21,22]. PC/PP CNT Nanocomposites [23] also showed exceptional electrical conductivity and high electromagnetic interference shielding [24]. One of the most important Carbons nanomaterials is Graphene Oxides (GO), which is similarly used as PP nanofiller to improve mechanical, thermal, and mechanical behavior [25]. Experimental comparison between PP, talc/PP, and pp/ Clay nanocomposites due to their mechanical and thermal parameters [26].

Moreover, PP was prepared with Cellulose nanowhiskers to upgrade PP properties [27]. It is reported that different classes of computational methods and molecular modeling were effectively utilized to elucidate different molecular properties, including physical, chemical, and thermal properties for many molecular systems. In contrast, the experimental approaches are limited or even unavailable [28-34]. Different researchers pointed out that some physical parameters such as TDM could be good indicators for molecular reactivity [35-40]. As the TDM is increased and bandgap energy decreased, the reactivity of the studied structure is increased. Another descriptor for reactivity and active site of the studied structure is indicated in terms of the charge on the surface. This could be indicated by mapping the molecular electrostatic potential (MESP), as stated earlier [41-46]. Through the distribution of colors, one can detect the active site on the given surface by mapping MESP .

Accordingly, molecular modeling at DFT: B3LYP/6-311g(d,p) level is utilized in the present computational work to study PP and PP's electronic properties interacted with $\mathrm{ZnO}$.

\section{Materials and Methods}

\subsection{Calculation details.}

Molecular models for PP and PP interacted with $\mathrm{ZnO}$ were formed, once the interaction through O then from Zn. By utilizing Gaussian 09 software [47] at Spectroscopy Department, National Research Centre, Egypt. The model structures are optimized using DFT theory at B3LYP/6-311g(d,p) level [48-50]. Physical parameters are calculated at the same level of theory, such as TDM and highest occupied molecular orbital and lowest unoccupied molecular orbital (HOMO/LUMO) band gap energy.

\section{Results and Discussion}

\subsection{Building model molecules.}

For calculating the electronic properties of $\mathrm{PP}$ and $\mathrm{PP} / \mathrm{ZnO}$ composites. At first, the model structures which represent $\mathrm{PP}$ and the interaction of $\mathrm{PP}$ with $\mathrm{ZnO}$ are designed. Models started by four units of PP monomers to represent PP molecule. The model structure of PP supposed structure is represented in figure 1. The interaction between PP with $\mathrm{ZnO}$ may occur through a hydrogen bond, so many probabilities are used to interact $\mathrm{ZnO}$ with PP molecule. The probabilities of interaction between $\mathrm{PP}$ and $\mathrm{ZnO}$ nano metal oxide, which be studied here, are through hydrogen atom with numbers $2,3,7,27,28,31,34$, and 37 representing the all 
supposed active sides of PP polymer. However, the interaction of $\mathrm{ZnO}$ with PP may be occurring according to two postulates, once through zinc $(\mathrm{Zn})$ and the other through oxygen (O) atom. So, two groups of postulates are simulated to report the study of all probabilities.

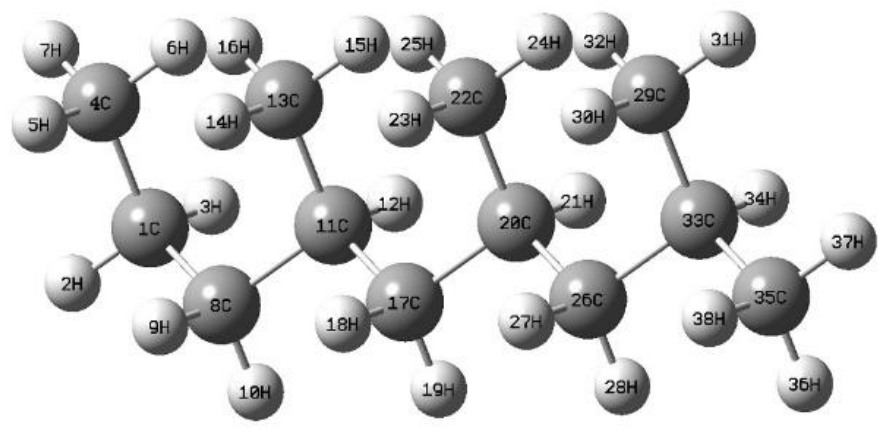

(a)

Figure 1. B3LYP/6-311g(d,p) optimized structure of polypropylene model molecule.

\subsection{Total dipole moment TDM and HOMO/LUMO band gap energy calculations.}

The prospects of PP polymer and PP nano composite with $\mathrm{ZnO}$ nanometal oxide occurring through hydrogen atom with numbers $2,3,7,27,28,31,34$ and 37 representing in figure 2, 3 and 4. TDM and HOMO/LUMO bandgap energy are important indicators for the electronic properties of polymeric materials. Where TDM is an indicator for material reactivity, and $\mathrm{HOMO} / \mathrm{LUMO}$ bandgap energy expresses the electronic type for the material (conductor, semiconductor, or insulator). TDM as Debye and HOMO/LUMO bandgap energy as eV for the model structures of PP polymer and postulate interaction of $\mathrm{ZnO}$ nano metal oxide according to the two postulate groups were calculated mentioned in table 1. Figure 2 showed the optimized structure and HOMO/LUMO bandgap of PP polymer.
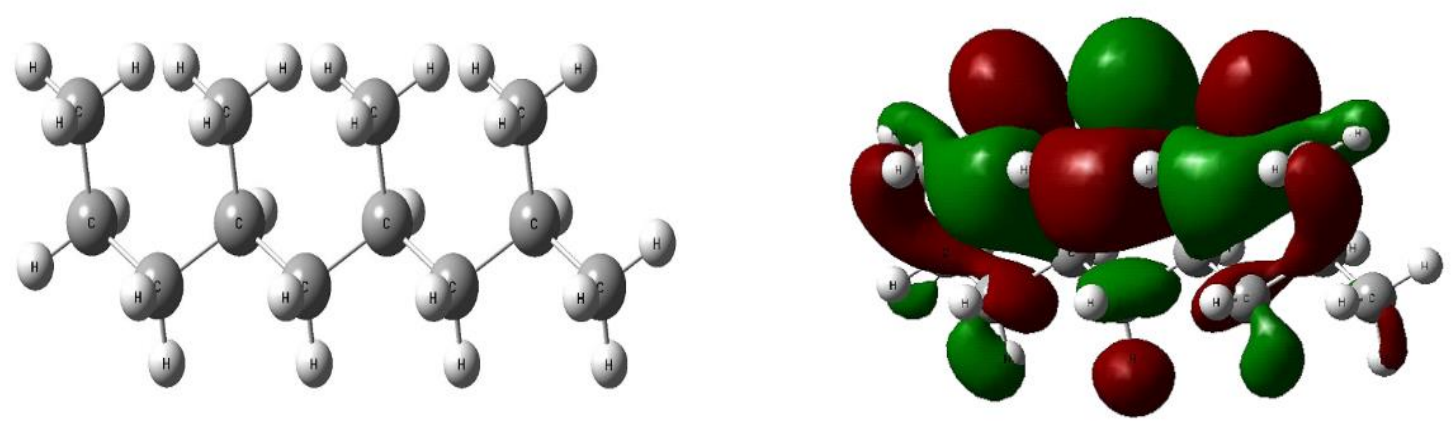

Figure 2. B3LYP/6-311g(d,p) optimized structure of polypropylene model molecule and calculated HOMO/LUMO band gap, respectively.

The first group of interactions between $\mathrm{PP}$ and $\mathrm{ZnO}$ through $\mathrm{Zn}$ atom $(\mathrm{PP} / \mathrm{ZnO})$ and its HOMO/LUMO band gap represented in figure 3. Meanwhile, in the second group of interactions between $\mathrm{ZnO}$ with $\mathrm{PP}$ through $\mathrm{O}$ atom $(\mathrm{PP} / \mathrm{OZn})$ represented according to figure 4. 


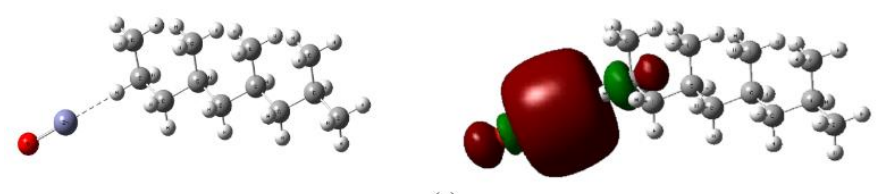

(a)
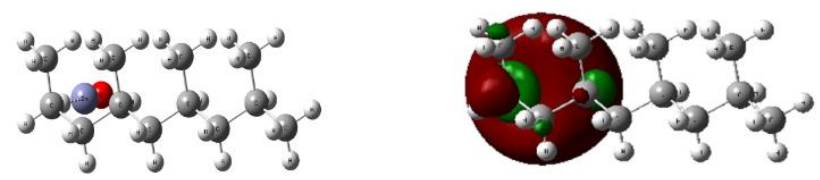

(b)
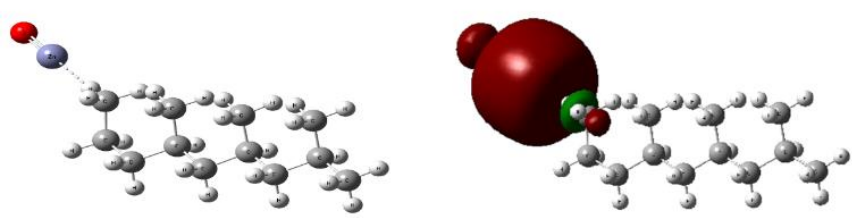

(c)
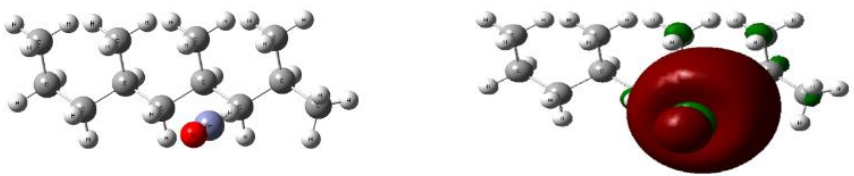

(d)
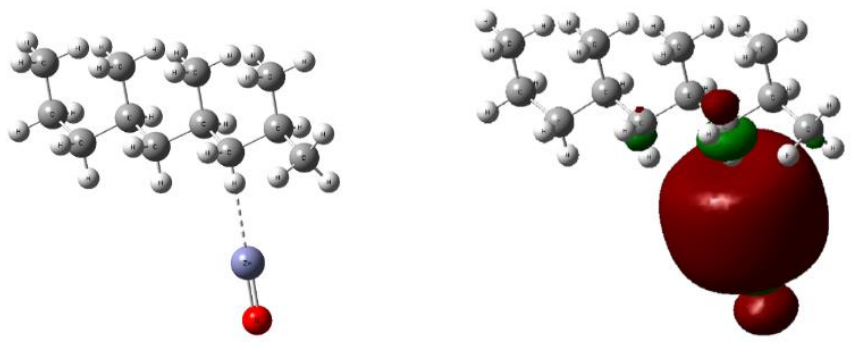

(e)
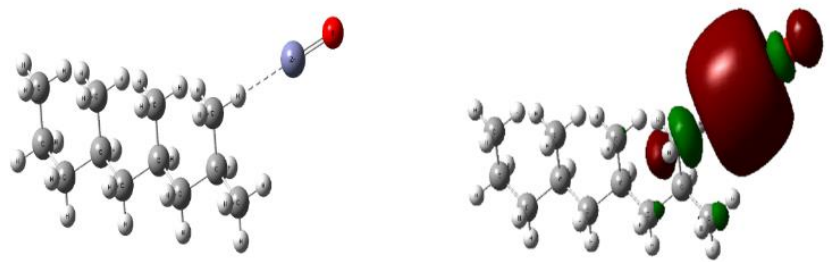

(f)
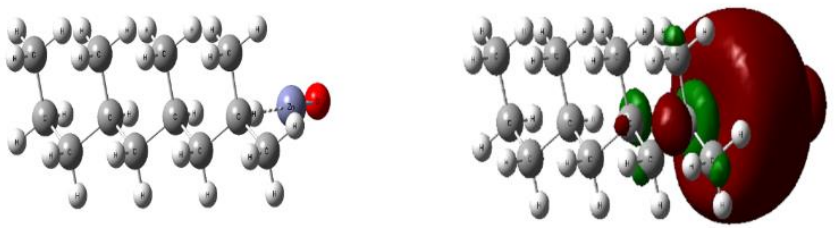

(g)

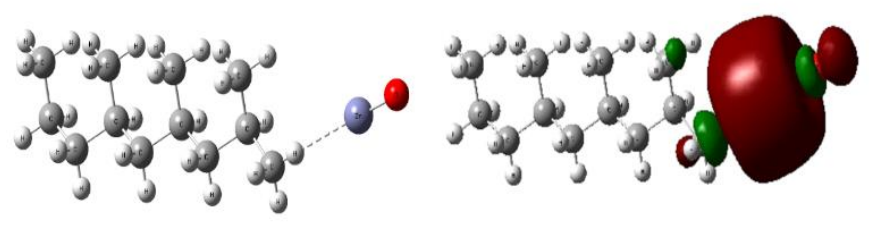

(h)

Figure 3. B3LYP/6-311g $(\mathrm{d}, \mathrm{p})$ optimized structure of polypropylene/ZnO whereas the interaction took place through $\mathrm{Zn}$ atom and HOMO/LOMU bandgap at a) PP H2 b) PP H3 c) PP H7 d) PP H27 e) PP H28 f) PP H31 g) PP H34 h) PP H37 

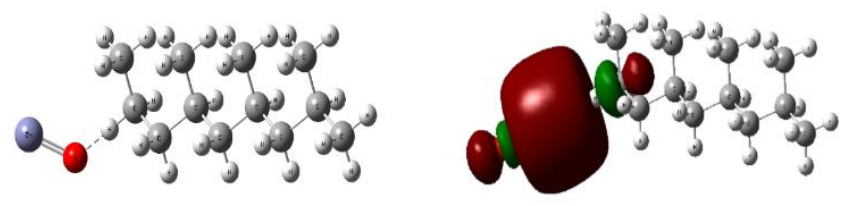

(a)
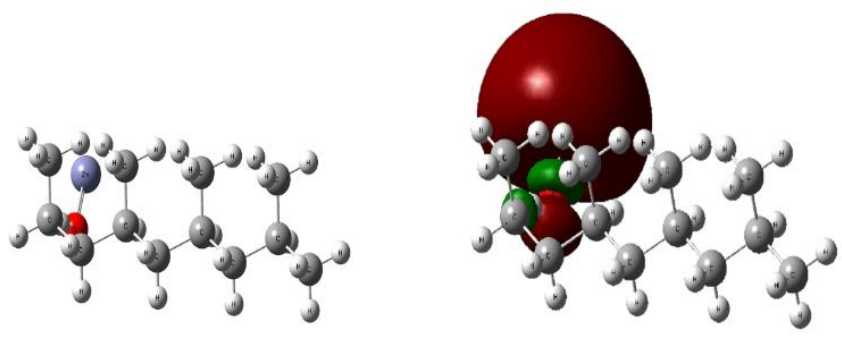

(b)
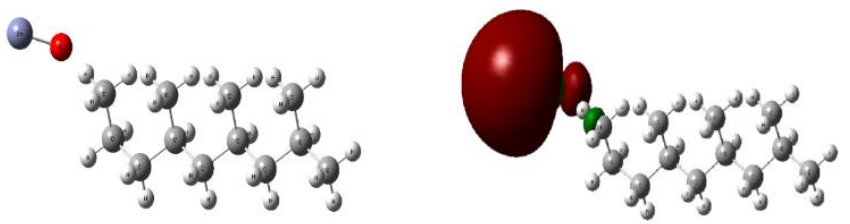

(c)
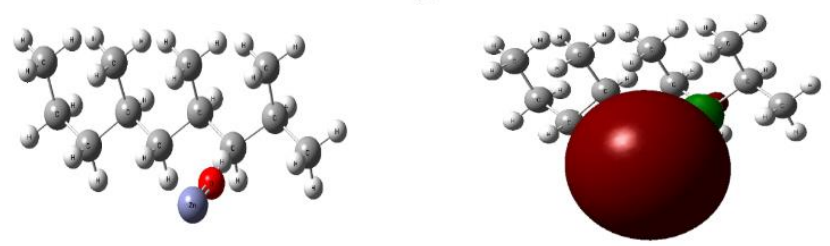

(d)
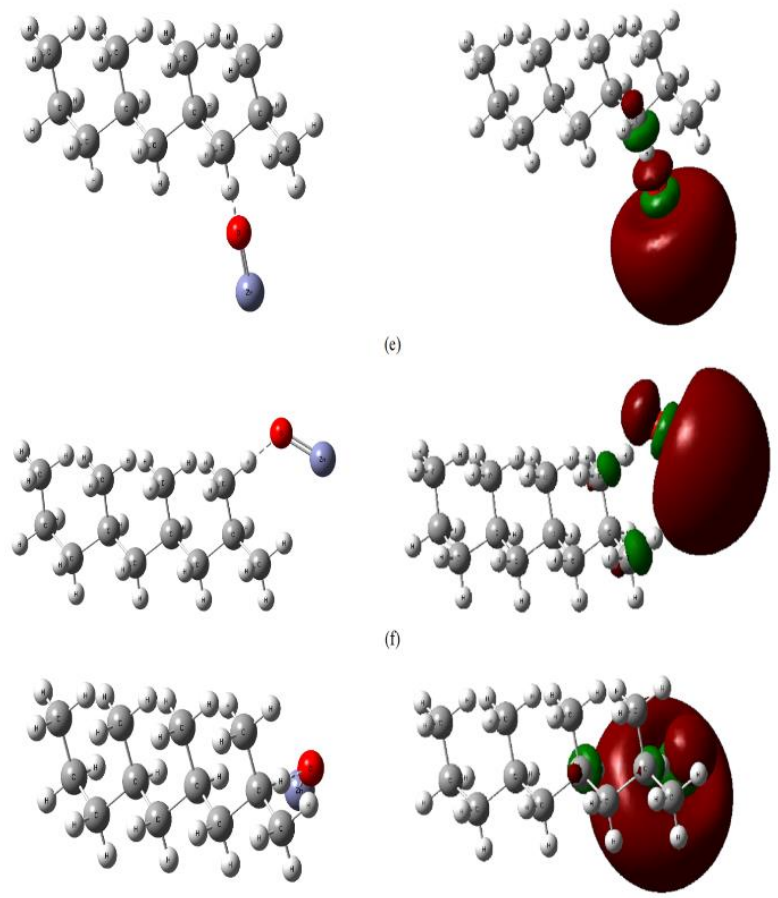

(g)

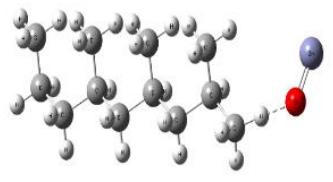

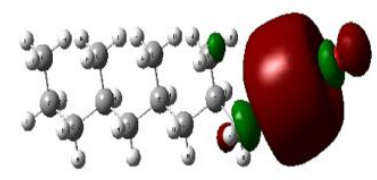

(h)

Figure 4. B3LYP/6-311g(d,p) optimized structure of polypropylene/ZnO whereas the interaction took place through Zn atom and HOMO/LOMU bandgap at a) PP H2 b) PP H3 c) PP H7 d) PP H27 e) PP H28 f) PP H31 g) PP H34 h) PP H37. 
Table 1. Calculated total dipole moment (TDM) as Debye and HOMO/LUMO band gap energy $(\Delta \mathrm{E})$ as eV using DFT theory B3LYP/6-311(d, p) level for PP and decorated PP with $\mathrm{ZnO}$ once through $\mathrm{Zn}$ atom and once through $\mathrm{O}$ atom for all postulate active sides.

\begin{tabular}{l|c|c} 
Structure & TDM & $\Delta \mathbf{E}$ \\
\hline PP & 0.4258 & 6.5307 \\
\hline PP+ZnO H2 & 7.5573 & 2.1737 \\
\hline PP+ZnO H3 & 6.5231 & 2.8999 \\
\hline PP+ZnO H7 & 6.9488 & 2.1715 \\
\hline PP+ZnO H27 & 7.0602 & 2.1601 \\
\hline PP+ZnO H28 & 7.5253 & 2.1897 \\
\hline PP+ZnO H31 & 7.8110 & 2.1780 \\
\hline PP+ZnO H34 & 6.2943 & 2.8741 \\
\hline PP+ZnO H37 & 6.6143 & 2.8436 \\
\hline PP+ OZn H2 & 4.3783 & 1.8950 \\
\hline PP+OZn H3 & 5.1155 & 1.8580 \\
\hline PP+OZn H7 & 3.7819 & 1.9160 \\
\hline PP+OZn H27 & 2.7877 & 2.3935 \\
\hline PP+OZn H28 & 4.2653 & 2.4548 \\
\hline PP+OZn H31 & 3.5172 & 1.7644 \\
\hline PP+ OZn H34 & 4.5434 & 1.9339 \\
\hline PP+OZn H37 & 5.2081 & 2.2969
\end{tabular}

Table 1 data TDM and bandgap energy $\triangle \mathrm{E}$ values for PP polymer were 0.4258 Debye and $6.5307 \mathrm{eV}$, respectively. For the first group that the interaction is occurring through $\mathrm{Zn}$ atom PP-ZnO, values of TDM for different postulate positions of interaction with supposed active sides H2, H3, H7, H27, H28, H31, H34, and H37 became 7.5573, 6.5231, 6.9488, 7.0602, 7.5253, 7.8110, 6.2943 and 6.6143 Debye meanwhile bandgap energy $\Delta \mathrm{E}$ valued became $2.1737,2.8999,2.1715,2.1601,2.1897,2.1780,2.8741$ and 2.8436 respectively. For all postulate positions, TDM was increased while bandgap energy $\Delta \mathrm{E}$ decreased, which indicates that all positions could affect by $\mathrm{ZnO}$ nano metal oxide. These results indicated $\mathrm{ZnO}$ 's high effect on the reactivity of PP molecule, where TDM of PP- $\mathrm{ZnO}$ composites higher than TDM of PP molecule several times. The highest value of TDM and lowest band gap energy $\Delta \mathrm{E}$ values are more affected by $\mathrm{ZnO}$ nano metal oxide decoration. The highest reactivity is at hydrogen atom number 2, 7,27, 31 with TDM, and lowest $\Delta \mathrm{E}$. From the calculations, $\mathrm{HOMO} / \mathrm{LUMO}$ bandgap energy $\Delta \mathrm{E}$ of PP molecule equals $6.5307 \mathrm{eV}$. These result in a match with the fact that $\mathrm{PP}$ is an insulating polymer. But, due to the interaction with $\mathrm{ZnO}$ the values of $\Delta \mathrm{E}$ decreased from 6.5307 to $(2.1737,2.8999,2.1715,2.1601,2.1897,2.1780,2.8741$ and 2.8436) $\mathrm{eV}$ at hydrogen atom number $(2,3,7,27,28,31,34$ and 37$)$ as presents in table 1. These results confirm the effect of $\mathrm{ZnO}$ on the electronic properties of $\mathrm{PP}$, where $\mathrm{PP}-\mathrm{ZnO}$ composites have $\Delta \mathrm{E}$ value lower than the value of $\Delta \mathrm{E}$ for PP molecule. In other words, PP$\mathrm{ZnO}$ composites became semiconductor materials. The lowest value for $\Delta \mathrm{E}$ was the interaction at hydrogen number 2, 7,27, and 31. These indicated that PP interaction with $\mathrm{ZnO}$ through $\mathrm{Zn}$ atom could occur with the atoms number $2,7,27$, and 31 .

Similarly, the second group of postulates of interaction between $\mathrm{ZnO}$ nano metal oxide and $\mathrm{PP}$ polymer occurring through $\mathrm{O}$ atom $\mathrm{PP}-\mathrm{OZn}$ was studied through the same hydrogen atoms $\mathrm{H} 2, \mathrm{H} 3, \mathrm{H} 7, \mathrm{H} 27, \mathrm{H} 28, \mathrm{H} 31, \mathrm{H} 34$, and H37. The values of TDM increased from 0.4258 for PP polymer to 4.3783, 5.1155, 3.7819, 2.7877, 4.2653, 3.5172, 4.5434, and 5.2081 Debye for PP decorated with $\mathrm{ZnO}$ nanometal oxide at hydrogen atom as presents in Table 1 also. These results clear that PP-OZn composites have TDM higher than TDM for PP molecule but less than the values of TDM is produced from the first group. However, the results of $\mathrm{HOMO} / \mathrm{LUMO}$ band gap energy $(\Delta \mathrm{E})$ clear that $\mathrm{PP}-\mathrm{OZn}$ composites have $\Delta \mathrm{E}$ values less than the value of $\Delta \mathrm{E}$ for $\mathrm{PP}$ molecule. E's value decreased from 6.5307 for $\mathrm{PP}$ to 
1.8950,1.8580,1.9160, 2.3935, 2.4548, 1.7644, 1.9339, and $2.2969 \mathrm{eV}$ for decorated PP with $\mathrm{ZnO}$ at hydrogen atom number $\mathrm{H} 2, \mathrm{H} 3, \mathrm{H} 7, \mathrm{H} 27, \mathrm{H} 28, \mathrm{H} 31, \mathrm{H} 34$, and $\mathrm{H} 37$ as presents in table 1. The second group $\Delta \mathrm{E}$ calculations clear that $\mathrm{E}$ 's values are less than values of $\Delta \mathrm{E}$ for the first group, and the lowest value of $\Delta \mathrm{E}$ was $1.7644 \mathrm{eV}$, corresponding to the interaction that may occur at hydrogen atom number 31 .

Accordingly, the decoration of $\mathrm{PP}$ with $\mathrm{ZnO}$ through $\mathrm{Zn}$ atom could have interacted as represented in figure 5 that the TDM and HOMO/LUMO band gap energy $(\Delta \mathrm{E})$ made a significant change 13.8571 Debye and $0.2781 \mathrm{eV}$ table 2. For the decoration of PP with $\mathrm{ZnO}$ through $\mathrm{O}$ atom, the interaction could be as element decoration at $\mathrm{H}$ number 31, the $\mathrm{H}$ of $\mathrm{CH}_{3}$ group. Finally, $\mathrm{ZnO}$ nano metal oxide's electronic properties affect the electronic properties of $\mathrm{PP}$ polymer even if interacted through $\mathrm{Zn}$ atom or $\mathrm{O}$ atom. The case of decorated PP polymer by $\mathrm{ZnO}$ through $\mathrm{Zn}$ atom will interact with $\mathrm{H}$ of $\mathrm{CH}_{3}$ group and $\mathrm{H}$ on the opposite side, which could be applied for sensing. Also, the case of decorated $\mathrm{PP}$ polymer by $\mathrm{ZnO}$ through $\mathrm{O}$ atom could be used as an element in sensor or optoelectronic devices.
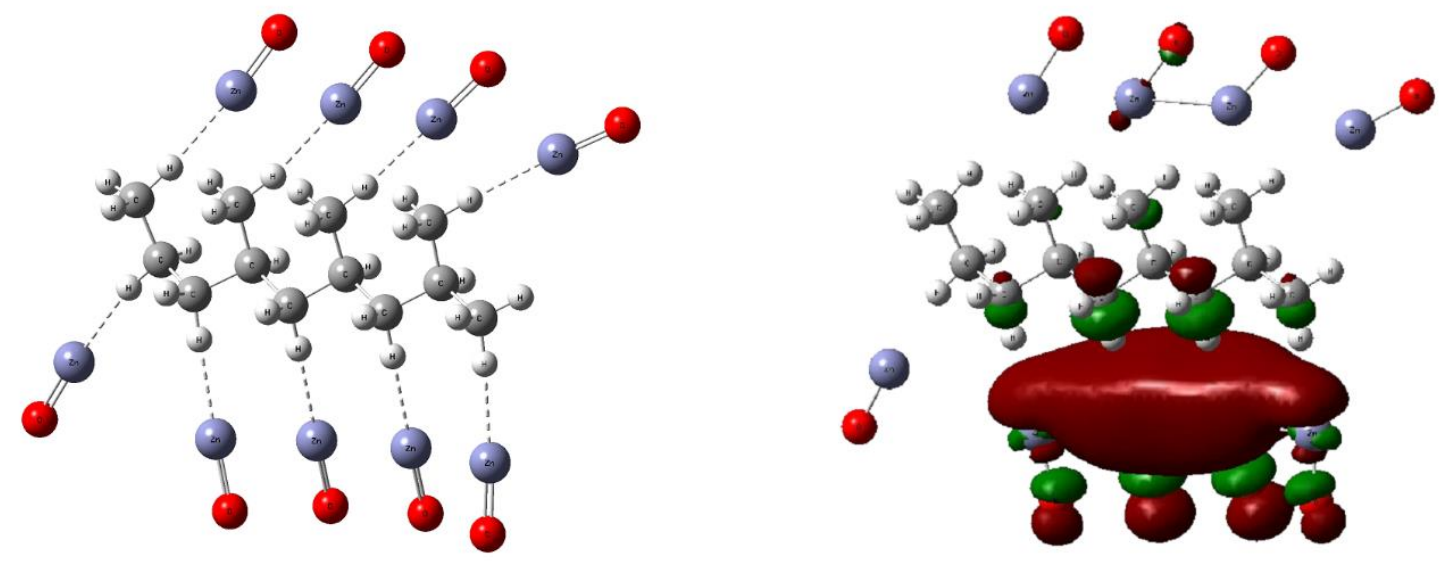

(a)

Figure 5. Decorated PP with $9 \mathrm{ZnO}$ through $\mathrm{Zn}$ atom optimized structures and HOMO/LOMU bandgap.

Table 2. Calculated total dipole moment(TDM) as Debye and HOMO/LUMO band gap energy $(\Delta \mathrm{E})$ as $\mathrm{eV}$ using DFT theory at B3LYP/6-311g(d,P) level for PP and decorated Polypropylene through $\mathrm{Zn}$ atom of $\mathrm{ZnO}$.

\begin{tabular}{l|l|l} 
Structure & TDM & $\Delta \mathbf{E}$ \\
\hline PP+ 9ZnO & 13.8571 & $\mathbf{0 . 2 7 8 1}$
\end{tabular}

\section{Conclusions}

The electronic properties of $\mathrm{PP}-\mathrm{ZnO}$ and $\mathrm{PP}-\mathrm{OZn}$ composites are calculated at quantum mechanical DFT: B3LYP/6-311g(d,P) level. The results of calculations that are running for the model structures appear the effect of $\mathrm{ZnO}$ on the values of TDM and $\triangle \mathrm{E}$. Where the value of TDM of PP molecule equal to 0.4258 Debye meanwhile, as a result to addition $\mathrm{ZnO}$ TDM values increased and reaches to 7.8110 Debye with the interaction which may occur at hydrogen atom number 31 in the first group. Also, the value of $\Delta \mathrm{E}$ decreased from $6.5307 \mathrm{eV}$ for PP molecule to $2.1780 \mathrm{eV}$ with the interaction, which may occur at hydrogen atom number 31 in the first group. The values of TDM of PP-OZn composites in the second group increased by the addition OZn molecule but less than the values of TDM in the first group. Meanwhile, $\Delta \mathrm{E}$ values in the second group are lower than $\Delta \mathrm{E}$ values in the first group and decreased to $1.7644 \mathrm{eV}$ Debye with the interaction, which may occur at hydrogen atom number. The present 
computational model, which is utilized in these calculations, proves that the studied physical parameters are good indicators for the studied polymer/metal oxide system's reactivity. These findings are in good agreement with the previous findings [51-55].

It could be concluded that the studied composites could be dedicated to sensors and other optoelectronic devices. The most probable interaction could be corresponding to the lowest value of $\Delta \mathrm{E}$. This achieved for the interaction of PP with OZn in the second group at hydrogen atom number.

\section{Funding}

This research received no external funding.

\section{Acknowledgments}

This research has no acknowledgment.

\section{Conflicts of Interest}

The authors declare no conflict of interest.

\section{References}

1. Othman, M.H.; Sulaiman, H.; bin Wahab, M.S. A Review of Polypropylene Nanoclay Nanocomposites: Preparation, Properties and Applications. Appl. Mech. Mater. 2014, 465-466, 944-948, https://doi.org/10.4028/www.scientific.net/AMM.465-466.944.

2. Vinay, K.; Amandeep, S. Polypropylene clay nanocomposites. Rev. Chem. Eng. 2013, 29, 439-448, https://doi.org/10.1515/revce-2013-0014.

3. Huang, C.K.; Chen, S.W.; Wei, W.C.J. Processing and property improvement of polymeric composites with added $\mathrm{ZnO}$ nanoparticles through microinjection molding. J. Appl. Polym. Sci. 2006, 102, 6009-6016.

4. Mahmud, S.; Abdullah, M.J. Nanotripods of Zinc Oxide. NanoSingapore 2006: IEEE Confe rence on Emerging Technologies - Nanoelectronics - Proceedings 1609767, 2006, pp. 442-446, https://doi.org/10.1109/NANOEL.2006.1609767.

5. Tang, J.; Wang, Y.; Liu, H.; Belfiore, L.A. Effects of organic nucleating agents and zinc oxide nanoparticles on isotactic polypropylene crystallization. Polymer 2004, 45, 2081-2091, https://doi.org/10.1016/j.polymer.2003.11.046.

6. Benabid, F.Z.; Kharchi, N.; Zouai, F.; Mourad, A.-H.I.; Benachour, D. Impact of co-mixing technique and surface modification of $\mathrm{ZnO}$ nanoparticles using stearic acid on their dispersion into HDPE to produce HDPE/ZnO nanocomposites. Polym. Polym. Compos. 2019, 27, 389-399, https://doi.org/10.1177/0967391119847353.

7. Badry, R.; Ibrahim, A.; Gamal, F.; Ibrahim, S.A.; Ezzat, H.; Elhaes, H.; Ibrahim, M. Modeling the Effect of Zinc Oxide on the Electronic Properties of Polyvinyl Alcohol. Egypt. J. Chem. 2020, https://doi.org/10.21608/EJCHEM.2020.27245.2564.

8. El-Khodary, S.A.; Yahia, I.S.; Zahran, H.Y.; Ibrahim, M. Preparation of polypyrrole-decorated $\mathrm{MnO}_{2} /$ reduced graphene oxide in the presence of multi-walled carbon nanotubes composite for high performance asymmetric supercapacitors. Physica $\quad$ B. 2019, 556, 66-74, https://doi.org/10.1016/j.physb.2018.11.070.

9. Bayoumy, A.M.; Refaat, A.; Yahia, I.S.; Zahran, H.Y.; Elhaes, H.; Ibrahim, M.A.; Shkir, M. Functionalization of graphene quantum dots (GQDs) with chitosan biopolymer for biophysical applications. Opt. Quantum Electron. 2019, 52, https://doi.org/10.1007/s11082-019-2134-z.

10. Refaat, A.; Ibrahim, M.A.; Elhaes, H.; Badry, R.; Ezzat, H.; Yahia, I.S.; Zahran, H.Y.; Shkir, M. Geometrical, vibrational and physical properties of polyvinyl chloride nanocomposites: Molecular modeling approach. J. Theor. Comput. Chem. 2019, 18, https://doi.org/10.1142/S0219633619500378.

11. Alghunaim, N.S.; El-Khodary, S.A.; Ibrahim, M.; El-Enany, G.M. Spectroscopic analyses of iron doped protonated polyaniline/graphene oxide system. Spectrochim. Acta A: 2019, 216, 349-358, https://doi.org/10.1016/j.saa.2019.03.053.

12. Ezzat, H.A.; Hegazy, M.A.; Nada, N.A.; Osman, O.; Ibrahim, M.A. Application of natural polymers enhanced with $\mathrm{ZnO}$ and $\mathrm{CuO}$ as humidity sensor. NRIAG J. Astron. Geophys. 2020, 9, 586-597, https://doi.org/10.1080/20909977.2020.1821573. 
13. Menazea, A.A.; Ezzat, H.A.; Omara, W.; Basyouni, O.H.; Ibrahim, S.A.; Mohamed, A.A.; Tawfik, W.; Ibrahim, M.A. Chitosan/graphene oxide composite as an effective removal of $\mathrm{Ni}, \mathrm{Cu}, \mathrm{As}, \mathrm{Cd}$ and $\mathrm{Pb}$ from wastewater. Comput.Theor. Chem.2020, 1189, https://doi.org/10.1016/j.comptc.2020.112980.

14. Lin, O.H.; Akil, H.M.; Mahmud, S. Effect of Particle Morphology on the Properties of Polypropylene/Nanometric Zinc Oxide (PP/Nanozno) Composites. Adv. Compos. Lett. 2009, 18, 77-83, https://doi.org/10.1177/096369350901800302.

15. Esthappan, S.K.; Nair, A.B.; Joseph, R. Effect of crystallite size of zinc oxide on the mechanical, thermal and flow properties of polypropylene/zinc oxide nanocomposites. Compos. B: Eng. 2015, 69, 145-153, https://doi.org/10.1016/j.compositesb.2013.08.010.

16. Keshavarzi, S.; Babaei, A.; Goudarzi, A.; Shakeri, A. ZnO nanoparticles as chain elasticity reducer and structural elasticity enhancer: Correlating the degradating role and localization of $\mathrm{ZnO}$ with the morphological and mechanical properties of PLA/PP/ZnO nanocomposite. Polym.Adv. Technol. 2019, 30, 1083-1095.

17. Abdel Hakim, A.E.; El-sawey, A.; Motawie, A.; Eid, A.; Mahrous, N. Study of Some Polypropylene Nanocomposite Properties. Egypt. J. Chem. 2018, 61, 825-842, https://doi.org/10.21608/ejchem.2018.3752.1340.

18. Roes, A.L.; Marsili, E.; Nieuwlaar, E.; Patel, M.K. Environmental and Cost Assessment of a Polypropylene Nanocomposite. J.Polym. Environ. 2007, 15, 212-226, https://doi.org/10.1007/s10924-007-0064-5.

19. Chiu, C.-W.; Lin, C.-A.; Hong, P.-D. Melt-spinning and thermal stability behavior of TiO2 nanoparticle/polypropylene nanocomposite fibers. J. Polym. Res. 2011, 18, 367-372, https://doi.org/10.1007/s10965-010-9426-0.

20. Fermino, D.M.; Oliani, W.L.; Andrade, C.G.B.; Lugão, A.B.; Parra, D.F.; Diaz, F.R.V. Mechanical Properties of Polypropylene Nanocomposites with Organoclay and Discarded Bond Paper, Characterization of Minerals, Metals, and Materials. Springer, Cham. 2015, 659-666, https://doi.org/10.1007/978-3-31948191-3_83.

21. Khare, V.; Srivastava, S.; Kamle, S.; Kamath, G.M. Effect of Filler Functionalization on the ThermoMechanical behavior of Polypropylene Nanocomposites. Procedia Structural Integrity 2019, 14, 215-225, https://doi.org/10.1016/j.prostr.2019.05.028.

22. Soitong, T.; Pumchusak, J. The relationship of crystallization behavior, mechanical properties, and morphology of polypropylene nanocomposite fibers. J. Mater. Sci. 2011, 46, 1697-1704, https://doi.org/10.1007/s10853-010-4987-1.

23. Chang, T.E.; Jensen, L.R.; Kisliuk, A.; Pipes, R.B.; Pyrz, R.; Sokolov, A.P. Microscopic mechanism of reinforcement in single-wall carbon nanotube/polypropylene nanocomposite. Polymer 2005, 46, 439-444, https://doi.org/10.1016/j.polymer.2004.11.030.

24. Poothanari, M.A.; Abraham, J.; Kalarikkal, N.; Thomas, S. Excellent Electromagnetic Interference Shielding and High Electrical Conductivity of Compatibilized Polycarbonate/Polypropylene Carbon Nanotube Blend Nanocomposites. Ind. Eng. Chem. Res. 2018, 57, 4287-4297, https://doi.org/10.1021/acs.iecr.7b05406.

25. Yuan, B.; Bao, C.; Song, L.; Hong, N.; Liew, K.M.; Hu, Y. Preparation of functionalized graphene oxide/polypropylene nanocomposite with significantly improved thermal stability and studies on the crystallization behavior and mechanical properties. Chem.l Eng. J. 2014, 237, 411-420, https://doi.org/10.1016/j.cej.2013.10.030.

26. Zhou, Y.; Rangari, V.; Mahfuz, H.; Jeelani, S.; Mallick, P.K. Experimental study on thermal and mechanical behavior of polypropylene, talc/polypropylene and polypropylene/clay nanocomposites. Mater. Sci. Eng.: A. 2005, 402, 109-117, https://doi.org/10.1016/j.msea.2005.04.014.

27. Bahar, E.; Ucar, N.; Onen, A.; Wang, Y.; Oksüz, M.; Ayaz, O.; Ucar, M.; Demir, A. Thermal and mechanical properties of polypropylene nanocomposite materials reinforced with cellulose nano whiskers. J. Appl. Polym. Sci. 2012, 125, 2882-2889, https://doi.org/10.1002/app.36445.

28. Ibrahim, M. Modeling the Effect of Zinc Oxide on the Electronic Properties of Polyvinyl Alcohol. Egypt. J. Chem. 2020, https://doi.org/10.21608/ejchem.2020.27245.2564.

29. Ezzat, H.; Gomaa, I.; El-Din, A.; Gawad, A.E.-D.; Osman, O.; Mahmoud, A.; Selim, M.; Elhaes, H.; Ibrahim, M. Semiempirical Molecular Modeling Analyses for Graphene/Nickel Oxide Nanocomposite. Lett. Appl. NanoBioScience 2020, 9, 1459-1466, https://doi.org/10.33263/LIANBS94.14591466.

30. Refaat, A.; Ibrahim, M.A.; Elhaes, H.; Badry, R.; Ezzat, H.; Yahia, I.S.; Zahran, H.Y.; Shkir, M. Geometrical, vibrational and physical properties of polyvinyl chloride nanocomposites: Molecular modeling approach. J. Theor. Comput. Chem. 2019, 18, https://doi.org/10.1142/S0219633619500378.

31. Bayoumy, A.M.; Ibrahim, M.; Omar, A. Mapping molecular electrostatic potential (MESP) for fulleropyrrolidine and its derivatives. Opt. Quantum Electron. 2020, 52, 1-13, https://doi.org/10.1007/s11082-020-02467-6.

32. Ezzat, H.; Badry, R.; Yahia, I.S.; Zahran, H.Y.; Ibrahim, A.; Elhaes, H.; Ibrahim, M. Mapping the Molecular Electrostatic Potential of Fullerene. Egypt. J. Chem. 2019, 62, 991-1002, https://doi.org/10.21608/EJCHEM.2019.5353.1472. 
33. El Gabaly, S.G.; Youssif, G.M.; Bayoumy, A.M.; Ezzat, H.; Elhaes, H.; Refaat, A.; Ibrahim, M. Modeling The Effect of Functional Groups on The Electronic Properties of Benzene; Pyridine and Pyrimidine. Egypt. J. Chem. 2019, 62, 1-11, https://doi.org/10.21608/ejchem.2019.12903.1807.

34. Ahmed, R.; Hanan, E.; Nabila, S.A.; Hanan, S.I.; Medhat, I. Green Route for the Removal of Pb from Aquatic Environment. CCHTS 2020, 23, 587-598, https://doi.org/10.2174/1386207323666200127123349.

35. Badry, R.; El-Khodary, S.; Elhaes, H.; Nada, N.; Ibrahim, M. The Influence of Moisture on the Electronic Properties of Monomer, Dimer, Trimer and Emeraldine Base Sodium Carboxymethyl Cellulose. Egypt. J.Chem. 2019, 62, 39-56, https://doi.org/10.21608/EJCHEM.2019.12805.1800

36. Bayoumy, A.; Youssif, G.; Elgohary, E.; Husien, S.; Salah, H.; Deen, E.; Albeltagy, N.; Abdelnaby, D.; Elhaes, H. Impact of solvation on the geometrical parameters of some amino acids. Lett. Appl. NanoBioScience 2019, 8, 567-570, https://doi.org/10.33263/LIANBS82.567570.

37. Ibrahim, A.; Elhaes, H.; Ibrahim M. Computational notes on the electronic properties of carboxylic acid. Lett. Appl. NanoBioScience 2020, 9, 1079 - 1082, https://doi.org/10.33263/LIANBS92.10791082.

38. Mohammadi-Rad, N.; Esrafili, M.D.; Sardroodi, J.J. CuN3 doped graphene as an active electrocatalyst for oxygen reduction reaction in fuel cells: A DFT study. J. Mol. Graph. Model. 2020, 96, https://doi.org/10.1016/j.jmgm.2020.107537.

39. Singh, S.; Kaur, I. Bandgap engineering in armchair graphene nanoribbon of zigzag-armchair-zigzag based Nano-FET: A DFT investigation. Physica E. 2020, 118, https://doi.org/10.1016/j.physe.2020.113960.

40. Mofidi, F.; Reisi-Vanani, A. Investigation of the electronic and structural properties of graphyne oxide toward CO, CO2 and NH3 adsorption: A DFT and MD study. Appl. Surf. Sci. 2020, 507, https://doi.org/10.1016/j.apsusc.2019.145134.

41. Abdelsalam, H.; Saroka, V.A.; Ali, M.; Teleb, N.H.; Elhaes, H.; Ibrahim, M.A. Stability and electronic properties of edge functionalized silicene quantum dots: A first principles study. Physica E. 2019, 108, 339346, https://doi.org/10.1016/j.physe.2018.07.022.

42. Grenni, P.; Barra Caracciolo, A.; Mariani, L.; Cardoni, M.; Riccucci, C.; Elhaes, H.; Ibrahim, M.A. Effectiveness of a new green technology for metal removal from contaminated water. Microchem. J. 2019, 147, 1010-1020, https://doi.org/10.1016/j.microc.2019.04.026.

43. Ibrahim, M.; El-Haes, H. Computational Spectroscopic Study of Copper, Cadmium, Lead and Zinc Interactions in the Environment. Int. J. Environ. Pollut. 2005, 23, 417-424, https://doi.org/10.1504/IJEP.2005.007604.

44. Ibrahim, M.; Mahmoud, A.A. Computational Notes on the Reactivity of some Functional Groups. J. Comput. Theor. Nanosci. 2009, 6, 1523-1526, https://doi.org/10.1166/jctn.2009.1205.

45. Politzer, P.; Laurence, P.R.; Jayasuriya, K. Molecular electrostatic potentials: an effective tool for the elucidation of biochemical phenomena. Environ. Health Persp. 1985, 61, 191-202, https://doi.org/10.1289/ehp.8561191.

46. Şahin, Z.S.; Şenöz, H.I.; Tezcan, H.; Büyükgüngör, O. Synthesis, spectral analysis, structural elucidation and quantum chemical studies of (E)-methyl-4-[(2-phenylhydrazono)methyl]benzoate. Spectrochim. Acta A 2015, 143, 91-100, https://doi.org/10.1016/j.saa.2015.02.032.

47. Frisch, M.; Trucks, G.; Schlegel, H.B.; Scuseria, G.E.; Robb, M.A.; Cheeseman, J.R.; Scalmani, G.; Barone, V.; Mennucci, B.; Petersson, G.J.I., Wallingford CT. gaussian 09, Revision d. 01, Gaussian. 20010, 201.

48. Becke, A.D. Density-functional thermochemistry. III. The role of exact exchange. J. Chem. Phys. 1993, 98, 5648-5652, https://doi.org/10.1063/1.464913.

49. Lee, C.; Yang, W.; Parr, R.G. Development of the Colle-Salvetti correlation-energy formula into a functional of the electron density. Phys. Rev. B. 1988, 37, 785-789, https://doi.org/10.1103/PhysRevB.37.785.

50. Miehlich, B.; Savin, A.; Stoll, H.; Preuss, H. Results obtained with the correlation energy density functionals of becke and Lee, Yang and Parr. Chem. Phys. Lett. 1989, 157, 200-206, https://doi.org/10.1016/00092614(89)87234-3.

51. Rahmati, M.; Jangali, M. Molecular dynamics simulation of proton conductivity enhancement in polymer membranes by Y-doped $\mathrm{BaCeO} 3$ nanoparticles. Comput. Mater. Sci. 2019, 169, https://doi.org/10.1016/j.commatsci.2019.109139.

52. Wu, J.; Wang, X.; Li, H.; Wang, F.; Hu, Y. First-principles investigations on the contact electrification mechanism between metal and amorphous polymers for triboelectric nanogenerators. Nano Energy 2019, 63, https://doi.org/10.1016/j.nanoen.2019.103864.

53. Zhou, M.; Xiong, X.; Drummer, D.; Jiang, B. Interfacial interaction and joining property of direct injectionmolded polymer-metal hybrid structures: A molecular dynamics simulation study. Appl. Surf. Sci. 2019, 478, 680-689, https://doi.org/10.1016/j.apsusc.2019.01.286.

54. Smith, A.L.; Capelli, E.; Konings, R.J.M.; Gheribi, A.E. A new approach for coupled modelling of the structural and thermo-physical properties of molten salts. Case of a polymeric liquid LiF-BeF 2 . J. Mol. Liq. 2020, 299, https://doi.org/10.1016/j.molliq.2019.112165.

55. Meza-González, B.; Gómez-Espinosa, R.M.; Cortés-Guzmán, F. Computational modeling of metal ions removal by a modified polypropylene membrane. Chem.l Phys. Lett. 2020, 749, https://doi.org/10.1016/j.cplett.2020.137452. 